\title{
CORPO ESPARGINDO
}

Captar a irregular existência que vem à luz no que se faz e diz.

Michel Foucault

A forma vibrante da nomeada maja tosca (Nery, 2013) figura feminina ou afeminada, estirada num canapé amarelo que emerge da sensualidade congelada de outros tempos, modos de ver e de transcrever ilumina as múltiplas representações ou reapresentação, ativa saberes / poderes nesse e desse dossiê. Assim, faz pensar o outro do corpo em suas problematizações como materialidade da natureza sensível, logo vulnerável. Um enigma que cada um enfrenta, constantemente, de maneira subjetiva e histórica. Como objeto de reflexão significa romper o dualismo entre a superioridade das ideias (espírito) contra a inferioridade do corpo (carne). Após a fratura provocada por Nietzsche, Freud, Foucault, Beauvoir e Butler entre outros/as como negar suas potencialidades de transgressão sociopolítica e de construção de subjetividade que transcendem a marca do sexo de modo a revisar a opressão, inclusive a da regulação sexual, questionando as dissonâncias entre identidades de gêneros e práticas sexuais que, como ponto de interlocução, abrem novas possibilidades epistemológicas

O Corpo na História e a História do Corpo foi tema de uma oficina do Laboratório de Estudos das Diferenças e Desigualdades Sociais (LEDDES) ligado ao Programa de Pós-Graduação em História da Universidade do Estado do Rio de Janeiro (UERJ). O experimento aconteceu no segundo semestre de 2014 como uma atividade da linha de pesquisa Vulnerabilidades e Controle Social. Pesquisadores/as de diferentes instituições se reuniram para compartilhar seus estudos sobre a emergência de um corpo/discurso que informa e conforma as complexas relações com a sociedade em sua invenção de si. O desafio era desnaturalizar o corpo/objeto para além da disciplina, procurando iluminar a violência dos regimes de verdade e suas obviedades que o aprisiona no biológico.

(...) o que é evidente é violento, mesmo se essa evidência é representada suavemente, liberalmente, democraticamente; o que é paradoxal, o que não cai sob o sentido, é menos violento, mesmo se for imposto arbitrariamente: um tirano que promulgasse leis extravagantes seria, finalmente, menos violento do que uma massa que se contentasse com enunciar o óbvio: o 'natural' é, em suma, o último dos ultrajes. (BARTHES, 1975: p. 92).

Está claro que existe uma bios neste corpo transformado em logos, em discursos da

Dossiê Transversos: O Corpo na História e a História do Corpo, Rio de Janeiro, v. 05; n. 05; Ano 02. dez. 2015. 
natureza e de natureza. $\mathrm{O}$ que se pretendeu foi inquirir para além do a priori de uma certa história natural que no século XVIII fundou as pesquisas e/ou debates sobre a existência dos gêneros, estabilidade das espécies, transmissão dos caracteres através das gerações e, que ainda define a sistematização de um certo corpo visível como domínio de saber.

A mutação da oficina ao dossiê e suas sistematizações só se justifica se não o reduzirmos ao procedimento pedagógico de um texto/produto mas, ao contrário, se ficarmos atentos às condições de possibilidades de saberes poderes que em seus discursos científicos ou ficcionais construíram enunciados sobre o corpo subjetivado como pornográfico, erótico, belo, escravizado, generificado, prostituído, violentado, encarcerado, clinicalizado ou matematizado. Como analisa Fábio Henrique Lopes, em Corpos trans! Visibilidade das violências e das mortes, a relação entre violência e transgêneros. Por meio de casos apresentados pela imprensa, o historiador problematiza os mecanismos de regulamentação, controle e naturalização da matriz heterossexual; bem como as diversas modalidades de agressão direcionadas aos "diferentes": aqueles que desfronteralizam a divisão binária de gênero e sexualidade e que, por isso, são alvo do "ódio heterossexista, cissexista e transfóbico".

A seguir em Corpos encarcerados em cena, Marilene Rosa Nogueira da Silva experimenta e se experimenta nos possíveis diálogos entre linguagem imagética e linguagem escrita. Estas criam novas identidades: a dos sujeitos dos documentários selecionados, as do Grupo de Informação sobre a prisão (GIP) e a do sujeito sobrevivente do diário/depoimento de um ex-presidiário do Carandiru. Um texto afetado que inquire a naturalização da carceralização e denuncia a banalização da violência e o descaso que a sociedade direciona aos indivíduos excluídos pela inclusão carcerária.

Problematizar a produção de jornais e contos considerados pornográficos no Rio de Janeiro, no momento da chamada Belle Époque é o que propõe Marina Vieira de Carvalho, em A ficcionalização do desejo: a pornografia e o erotismo como objetos de consumo na modernização da cidade do Rio de Janeiro. Com esse fim, traça os diferentes significados que os termos pornografia e erotismo tiveram na modernidade ocidental, para assim compreender o desenvolvimento do mercado editorial de temas lascivos na capital do país. A historiadora analisa os potenciais de transgressão e crítica que a pornografia de então tecia em suas relações com a sociedade carioca.

Antropologia criminal e prostituição: a matematização do corpo segundo Pauline Tarnowsky emerge das inquietações provocadas na sala de aula pelo filme L'Apollonide: Os

Dossiê Transversos: O Corpo na História e a História do Corpo, Rio de Janeiro, v. 05; n. 05; Ano 02. dez. 2015. 
amores da Casa de Tolerância ( 2011). A Professora Laura Nery e os graduandos José Roberto Silvestre Saiol e Beatriz do Nascimento Prechet discutem a normalização e controle moral na sociedade vitoriana, especificamente, a relação entre antropologia criminal e prostituição no final do século XIX. Em destaque o estudo da médica Pauline Tarnowsky, no Hospital de Kalinkine, em São Petersburgo, (1889) na classificação das prostitutas como degeneradas moral e fisicamente, identificação fundamentada na matematização dos seus corpos.

José Ricardo Ferraz em Ninguém nasce bela, torna-se bela. 'Miss Brasil': beleza e gênero (1950 - 1980), elege o concurso da Miss Brasil como possibilidade de análise da constituição do gênero feminino no Brasil, no período de 1950 a 1980 como modelo de beleza e seus efeitos de poder para além do estético. A partir de Beauvoir, com elaborações que transcendem a marca do sexo como por exemplo em Judith Butler, procura destacar o dualismo que matematizava o corpo feminino por meio de um olhar masculino. Logo, tornar-se bela emerge como um dispositivo que (con)formava o comportamento considerado adequado para as mulheres, reforçando os valores da chamada "boa sociedade".

Maria Elizabeth Ribeiro Carneiro, literalmente, ilumina em Fotografia e história, a existência e o vestígio remanescente: corpos negros de mulheres no 'teatro de enunciados' do Brasil oitocentista. São corpos ressignificados como cativos, que podem ser adquiridos, comprados, consumidos, vendidos. Apresenta a ama de leite como corpo/monumento de famílias que desejavam demonstrar sua distinção social, demarcar e, ao mesmo tempo, suavizar, fronteiras hierárquicas entre as "mães pretas" e seus pequenos/grandes senhores brancos. Imagens que não ilustram, mas sim constituem essa realidade social e que, por isso, possibilitam as memórias/dizíveis de como a "sociedade de bem" gostaria de ser lembrada pela posteridade.

Para encerrar Corpos escravizados: que histórias contam?, Iamara da Silva Viana analisa os manuais médicos sobre os corpos dos escravos, com destaque para o médico francês JeanBaptiste Alban Imber que chegou ao Brasil em 1831, momento em que as leis contra o tráfico de escravos estavam em pauta. O discurso médico é pensado como estratégia biopolítica que orienta os senhores na hora de comprar e de preservar a produtividade do escravo como corpo/ mercadoria. O estudo propõe investigar os efeitos desta normatividade no debate sobre o fim do tráfico de africanos que eleva o saber médico como um mecanismo de ampliação da vida útil do corpo escravizado.

Esses são apenas alguns fios de uma complexa trama do movimento contínuo da transgressão no sentido de um dos ditos de Foucault (1983) em homenagem a Bataille:

Dossiê Transversos: O Corpo na História e a História do Corpo, Rio de Janeiro, v. 05; n. 05; Ano 02. dez. 2015. 


\begin{abstract}
A transgressão é um gesto relativo ao limite; $\mathrm{O}$ jogo dos limites e da transgressão parece ser regido por uma obstinação simples: a transgressão transpõe e não cessa de recomeçar a transpor uma linha que, atrás dela, imediatamente, se fecha de novo em um movimento de tênue memória, recuando então novamente para o horizonte do intransponível. Mas esse jogo vai além de colocar em ação tais elementos: ele os situa em uma incerteza, em certezas logo invertidas nas quais o pensamento, rapidamente, se embaraça por querer apreendê-las (...) A transgressão não está, portanto, para o limite como o negro está para o branco, o proibido para o permitido, o exterior para o interior, o excluído para o espaço protegido da morada. Ela está mais ligada a ele por uma relação em espiral que nenhuma simples infração pode extinguir. Talvez alguma coisa como o relâmpago na noite que, desde tempos imemoriais, oferece um ser denso e negro ao que ela nega, o ilumina por dentro e de alto a baixo, deve-lhe entretanto sua viva claridade, sua singularidade dilacerante e ereta, perde-se no espaço que ela assinala com sua soberania e, por fim, se cala, tendo dado um nome ao obscuro. Nada é negativo na transgressão. Ela afirma o ser limitado, afirma o ilimitado no qual ela se lança, abrindo-o pela primeira vez à existência.
\end{abstract}

Desta feita o Dossiê se inscreve como um vestígio, uma caixa de ferramenta, propondo-se a desnudar o êxtase da naturalização. Enfim, um exercício que objetiva fazer aparecer o corpo como um sujeito histórico, mutável, insistente e visível como um lugar onde habita o poder. Compartilhem da transgressão positivada de pesquisadores/as que ousaram apresentar suas reflexões de forma problemática, sem as certezas e verdades acabadas, ainda em plena dinâmica e provocação como sua maja que se quer tosca.

Marina Vieira de Carvalho Marilene Rosa Nogueira da Silva

Rio de Janeiro 30 de novembro de 2015

\title{
Como citar:
}

CARVALHO, Marina Vieira de; SILVA, Marilene Rosa Nogueira da. Corpo Espargindo. Revista Transversos. "Dossiê: O Corpo na História e a História do Corpo". Rio de Janeiro, Vol. 05, n⿳‥ 05, pp. 04-07, Ano 02. dez. 2015. Disponível em: <http://www.e-publicacoes.uerj.br/ index.php /transversos >. ISSN 2179-7528. DOI: 10.12957/transversos.2015.19792. 